\title{
Breve histórico da gestão escolar na educação infantil a partir da constituição de 1988
}

Até os anos de 1970, pouco ou quase e nada foi feito para que a legislação vigente garantisse a provisão de educação infantil. Somente nos anos de 1980 a sociedade civil organizada e grupos de pressão ligados a pauta da educação tiveram êxito na luta pela incorporação desse nível de ensino ao texto constitucional A educação, de uma forma geral, passa por um momento de significativas transformações em suas práticas e concepções de ensino. 0 objetivo do artigo é descrever, brevemente, aspectos da gestão e qualidade escolar da Educação Infantil após a Constituição Federativa de 1988, levando em consideração aspectos da gestão como um mecanismo de participação democrática. Para a realização da pesquisa foi utilizado o procedimento metodológico da revisão bibliográfica e documental. Compreende-se que a gestão na educação infantil, atualmente, é pautada por aspectos de colaboração participativa e valorização da formação continuada para que os profissionais da educação se adequem as novas demandas educacionais. Os esforços caminham para a integração do cuidar e educar como concepção integrante do processo educativo, buscando novas práticas pedagógicas que acompanhem o desenvolvimento da criança, considerando as suas peculiaridades, valorizando a diversidade para a compreensão do outro e do mundo, no objetivo de uma educação integral.

\section{Brief history of school management in childhood education from the 1988 Constitution}

Until the 1970, little or almost nothing was done for the current legislation to guarantee the provision of early childhood education. Only in the 1980 s did organized civil society and pressure groups linked to the agenda of education succeed in the struggle to incorporate this level of education into the constitutional text Education, in general, goes through a moment of significant changes in its practices and teaching conceptions. The purpose of the article is to briefly describe aspects of school management in Early Childhood after the 1988 Federal Constitution, taking into account aspects of management as a mechanism for democratic participation. To carry out the research, the methodological procedure of bibliographic and documentary review was used. It is understood that the management in early childhood education, currently, is guided by aspects of participatory collaboration and valuation of continuing education so that education professionals adapt to the new educational demands. Efforts are moving towards the integration of caring and educating as an integral concept of the educational process, seeking new pedagogical practices that accompany the child's development, considering their peculiarities, valuing diversity for the understanding of the other and the world, in the aim of an education integral.

Keywords: Democratic Management; 1988 Federal Constitution; Early Childhood Education.

Topic: Pedagogia (Educação Criança e Adolescente)

Reviewed anonymously in the process of blind peer.
Received: 24/10/2020

Approved: 25/01/2021
Eduardo Paiva Oliveira (iD

Universidade Cidade de São Paulo, Brasil http://lattes.cnpq.br/8293318835514659

http://orcid.org/0000-0003-3321-4825 edu.paiva@yahoo.com.br

\section{Referencing this:}

OLIVEIRA, E. P.. Breve histórico da gestão escolar na educação infantil a partir da constituição de 1988. Educationis, v.9, n.1, p.30-38, 2021. DOI: http://doi.org/10.6008/CBPC2318-3047.2021.001.0004 


\section{INTRODUÇÃO}

A educação infantil é o início do ciclo escolar da criança na educação básica, sendo de extrema importância que a criança tenha seu desenvolvimento garantido nos aspectos: intelectivo, social, físico e psicológico, o acompanhamento desse ciclo foi necessário para que se reduzisse os casos de negligência nas escolas nessa fase de aprendizagem. A Constituição Federal de 1988 representou o marco inicial para que a educação infantil fosse reconhecida como direito de educação e sociabilização para as crianças brasileiras.

Por meio da pressão de movimentos no mundo inteiro, a Educação Infantil ganhou notoriedade em produções científicas sobre o desenvolvimento na infância e a importância de uma boa base educacional. Sendo assim, os estudos impactaram em mudanças organizacionais nas Instituições escolares para que pudessem ofertar vivencias de aprendizagens significativas para as crianças, o que também implicou em uma nova prática gestora e docente.

Com isso a pesquisa se dá pelas exigências para a gestão na Educação Infantil a partir das reflexões para a educação advindas da Constituição Federal de 1988. O tema se faz relevante pela importância de contribuir com as reflexões acerca de uma educação pública de qualidade desde a primeira infância que objetive uma formação integral pautada na cidadania.

$\mathrm{O}$ artigo pretende responder os seguintes problemas de pesquisa: quais foram as transformações ocorridas na educação infantil? Quais os objetivos das práticas de gestão para a Educação Infantil? Como é avaliada a qualidade nessa fase de ensino?

Para a realização da pesquisa foram consultados documentos legislativos que regularizam a educação no Brasil, como a Constituição Federativa do Brasil de 1988, o Estatuto da Criança e do Adolescente de 1990, a Lei de Diretrizes e Bases para a Educação Nacional (1996) entre outros, além de obras de autores que abordam a questão e artigos científicos.

O objetivo do trabalho é descrever as transformações nas propostas educacionais para a Educação Infantil, considerando as práticas de gestão e os parâmetros de qualidade diante das novas demandas educacionais para essa fase, resultantes das novas reflexões e debates.

\section{MATERIAIS E MÉTODOS}

Para a realização do artigo foi adotado o procedimento metodológico da revisão bibliográfica e documental. A análise do conteúdo e a abordagem para a produção do trabalho foi qualitativa. Em primeiro momento foram consultados obras e artigos científicos em plataformas de repositórios digitais como Google Scholar, Scielo e Biblioteca Digital Brasileira de Dissertações e Teses, utilizando os seguintes descritores de pesquisa: Educação Infantil; qualidade na educação; gestão na educação infantil. Após a leitura e fichamento do material selecionado, partiu-se para a revisão documental, a qual levou a pesquisa para a plataforma do Ministério da Educação e Cultura, Senado, Câmara e Organização das Nações Unidas. 


\section{RESULTADOS E DISCUSSÃO}

A educação infantil iniciou o seu percurso vinculado a duas realidades, uma assistencialista, cujas crianças ficavam em creches e casas maternais pela necessidade da mãe trabalhar, geralmente eram crianças em condições de pobreza e até mesmo desnutridas e outra, das crianças matriculadas em pré-escolas e jardins de infância, onde recebiam socialização e educação, porém todas as instituições para crianças estavam envolvidas em um projeto, para algumas assistencialista e para outras educacional (LUCAS, 2009).

A educação assistencialista das creches e a educação da pré-escola caminharam paralelamente durante muito tempo, como ressalta Andrade (2010): “A história dos dispositivos legais acerca da infância, seus direitos e sua educação retrata um percurso histórico marcado por programas fragmentados e relações antagônicas entre a assistência e a educação".

A educação infantil, ou educação da primeira infância, passou a ser pautada em escala global por diretrizes de órgãos multilaterais, como a Unesco, ONU e Cepal em um movimento posterior ao Consenso de Washington, datado da década de 1980 e que esteve em vigor até o início dos anos 2000. Isso seria uma espécie de resposta à agenda até então vigente, pautada pelo incentivo a adoção de programas de ajustes fiscais por parte dos países periféricos, que ao levarem a prática tal receituário, submeteram suas populações à níveis cada vez mais graves de miserabilidade, o que acabou por refletir diretamente na qualidade de vida das crianças na primeira infância.

Segundo Campos (2012) “Esses programas, associados a aspectos estruturais decorrentes da própria crise do processo acumulativo vigente, produziram massas de desempregados e subempregados, jogando milhares de trabalhadores em situação de miséria ou pobreza absoluta". Nesse cenário, haveria surgido uma nova questão social denominada de "infantilização da pobreza ", que passou a se fazer presente em diversos tipos de relatórios de organismos multilaterais.

Frente a esse contexto, cabe citar o Fórum Mundial de Educação que aconteceu em Dakar, Senegal, no ano 2000, que contou com a presença de representantes de 164 governos e culminou na construção do Marco de Ação de Dakar, Educação para Todos: Cumprindo nossos Compromissos Coletivos. Segundo descrição do próprio documento, tratava-se de estipular 6 objetivos para a educação global de amplo alcance a serem cumpridos até o ano de 2015.

Neste marco, temos os objetivos 1 e 2 com algum tipo de interface com a educação infantil, sendo eles: Objetivo 1 - Educação e cuidados na primeira infância - "Expandir e melhorar educação e cuidados na primeira infância, principalmente para as crianças mais vulneráveis e em situação desfavorável" e Objetivo 2 - Educação primária universal - "Garantir que, até 2015, todas as crianças, principalmente meninas, crianças em circunstâncias difíceis e as pertencentes a minorias étnicas, tenham acesso a uma educação primária completa, gratuita, obrigatória e de boa qualidade" (UNESCO, 2001).

Ainda em se tratando da influência de organismos multilaterais na agenda voltada a educação infantil nos países subdesenvolvidos, o que se percebe são resultados danosos em certo sentido. Rosemberg (2013), aponta para o fato de linhas de financiamento para educação básica providas pelo Banco Mundial a partir 
dos anos de 1990 estavam atreladas a adoção de modelos não formais de educação, que demandavam baixo investimento público. Proposições como essas estariam em consonância com agenda de austeridade preconizada por esses órgãos, que se de um lado buscavam apresentar soluções que pelo menos em parte contornassem o problema da falta de políticas para a primeira infância, por outro, tinham uma preocupação ainda maior na manutenção do quadro de austeridade fiscal.

\section{Histórico da política de educação infantil no Brasil}

Por séculos a educação esteve exclusivamente a cargo das famílias. Na sociedade contemporânea, chegamos a uma configuração diferente, em que as crianças passam a ter direito a um ambiente de socialização e aprendizado externo. No caso brasileiro especificamente, com a crescente entrada da mulher no mercado de trabalho a partir da década de 1930, surgiram as primeiras tentativas de organização de creches. Segundo Rosemberg (2013) também havia uma necessidade constituída de amparar filhos de mulheres viúvas em dificuldades financeiras e tratar de crianças órfãs que, em muitos casos, estavam em situação de rua. Havia nisso também um viés higienista, no sentido de que covinha "limpar" a paisagem urbana da prática de mendicância.

Para Paschoal et al. (2009), na esfera pública à época, forma-se também um consenso quanto à necessidade prover uma instância de atenção fora dos seios das famílias. Quanto a isso, fatores como os elevados índices de mortalidade infantil, os inúmeros casos de acidentes fatais envolvendo crianças, um quadro devastador de desnutrição e todo o quadro de miserabilidade que enfrentavam crianças de famílias de baixa renda ajudariam a moldar a opinião pública.

Com isso, setores da igreja, organizações empresariais, instituições filantrópicas e afins passaram projetar soluções para o problema em tela:

Enquanto para as famílias mais abastadas pagavam uma babá, as pobres se viam na contingência de deixar os filhos sozinhos ou colocá-los numa instituição que deles cuidasse. Para os filhos das mulheres trabalhadoras, a creche tinha que ser de tempo integral; para os filhos de operárias de baixa renda, tinha que ser gratuita ou cobrar muito pouco; ou para cuidar da criança enquanto a mãe estava trabalhando fora de casa, tinha que zelar pela saúde, ensinar hábitos de higiene e alimentar a criança. A educação permanecia assunto de família. Essa origem determinou a associação creche, criança pobre e o caráter assistencial da creche. (DIDONET, 2001)

Adquirindo caráter público e formal apenas a partir do século $\mathrm{XX}$, a escola e a educação infantil passaram a contar com mão de obra especializada e uma diretriz programática para o ensino, isso se deu através da Constituição Federal de 1988. Anteriormente, as Constituições não tratavam especificamente da educação. A Constituição Federal de 1934, em seus artigos 148 a 158 tratou vagamente sobre a educação brasileira, quando se refere ao compromisso da União em incentivar o desenvolvimento da arte, da ciência e da cultura brasileira e assim ocorreu com as demais Constituições, em que vagamente abordagem a questão da educação nacional.

\section{A educação infantil na legislação brasileira}

Até os anos de 1970, pouco ou quase e nada foi feito para que a legislação vigente garantisse a 
provisão de educação infantil. Somente nos anos de 1980 a sociedade civil organizada e grupos de pressão ligados a pauta da educação tiveram êxito na luta pela incorporação desse nível de ensino ao texto constitucional (PASCHOAL et al., 2009).

E aqui chega-se a um ponto de grande convergência na trajetória da educação infantil na legislação brasileira. Isso porque a Constituição Federal, em seu artigo 208, inciso IV, é muito categórica ao estabelecer o direito à educação na primeira infância: "IV: [...] O dever do Estado para com a educação será efetivado mediante a garantia de oferta de creches e pré-escolas às crianças de zero a seis anos de idade" (BRASIL, 1988).

Essa previsão foi muito importante para se combater a concepção de que a educação na primeira infância seria algo vinculado a assistência social ou algum tipo de atividade caritativa, algo que vigorava até então. E somado a essa previsão da Constituição Federal de 1988, dois anos depois, tivemos a aprovação do Estatuto da Criança e do Adolescente - ECA.

A Lei N. 8.069 de 1990, que estabeleceu o ECA transferiu a responsabilidades da educação infantil para os municípios, criando o Conselho Tutelar, o Fundo Municipal e o Conselho Municipal. Segundo o ECA (1990) a criança - considerado o indivíduo de 0 a 12 anos - e o adolescente - de 12 a 18 anos - tem direito a educação, a cultura e ao aprendizado profissionalizante. Em seu artigo n. 53ㅇ dispõe sobre esses direitos no que se refere:

\footnotetext{
I - Igualdade de condições para o acesso e permanência na escola;

II - Direito de ser respeitado por seus educadores;

III - Direito de contestar critérios avaliativos, podendo recorrer às instâncias escolares superiores;

IV - Direito de organização e participação em entidades estudantis;

V - Acesso à escola pública e gratuita próxima de sua residência.

$\mathrm{V}$ - Acesso à escola pública e gratuita, próxima de sua residência, garantindo-se vagas no mesmo estabelecimento a irmãos que frequentem a mesma etapa ou ciclo de ensino da educação básica. (BRASIL, 1990)
}

Dessa forma a educação passa a ser direito subjetivo da criança e do adolescente, firmando-se na legislação brasileira, como compromisso da União, dos estados e dos Municípios, objetivando uma formação integral e destinada para o exercício pleno da cidadania.

Desde então a educação infantil ganhou importância significativa nos assuntos do governo, sendo a matrícula de crianças de 0 a 6 anos garantida como direito em creches e pré-escolas em todo o território nacional.

Em 1996, é a aprovada a Lei N. 9.394, que institui as Diretrizes e Bases para a Educação Nacional (LDB), através dessa lei a educação infantil passa a ser vista como primeira etapa do ensino básico, resultado de inúmeras pesquisas que mostraram que os anos iniciais de ensino eram cruciais para o desenvolvimento escolar e social posterior da criança, como em Freud e Piaget que estabelecem críticas a educação a partir de reflexões e estudos comportamentais das crianças.

O artigo 1 o da LBD afirma:

Art. 1‥ A educação abrange os processos formativos que se desenvolvem na vida familiar, 
na convivência humana, no trabalho, nas instituições de ensino e pesquisa, nos movimentos sociais e organizações da sociedade civil e nas manifestações culturais. (BRASIL, 1996)

Dessa forma enfatiza que a educação é um processo em constante movimento na sociedade, onde todos os agentes devem estar envolvidos. A LDB afirma ainda que a educação infantil deve ocorrer na escola como complemento à educação dada pela família, essa aliança educacional é reforçada no Plano Nacional de Educação (PNE) instituído em 2001, atualizado em 2014.

\section{O novo modelo de Gestão a partir da Lei de Diretrizes e Bases de 1996}

Adquirindo caráter público e formal apenas a partir do século XX, a escola e a educação infantil passaram a contar com mão de obra especializada e uma diretriz programática para o ensino, isso se deu através da Constituição Federal de 1988 (ANDRADE, 2010).

O Ministério da Educação (MEC), em uma publicação sobre os Indicadores de Qualidade na Educação Infantil de 2009, enumerou alguns critérios e conceitos sobre a efetiva qualidade para o ensino infantil. 0 primeiro indicador diz respeito aos aspectos federais legais contidos na Constituição Federal de 1988 e no Estatuto da Criança e do Adolescente de 1990, que priorizam os fundamentos dos direitos humanos universais sobre a educação.

O segundo indicador de qualidade na educação apontado pelo MEC (BRASIL, 2009) é o respeito e valorização da diversidade cultural, gênero, diferenças religiosas, étnicas-raciais e da inclusão de pessoas com deficiência física. O que torna o aspecto formativo da criança ético e voltado para o exercício da cidadania.

O terceiro fator de qualidade leva em conta a prática pedagógica das questões ambientais e a educação voltada para uma relação mais solidária entre as pessoas, já como quarto fator de qualidade na educação, O MEC (BRASIL, 2009) aponta os objetivos contidos nos documentos legislativos para a educação no Brasil.

Em quinto e último lugar, é dado ênfase para o conhecimento sobre o desenvolvimento cognitivo e social da criança, levando em conta aspectos socioculturais, ambientais e afetivos, para tanto é necessário atentar a formação dos profissionais da educação infantil (BRASIL, 2009).

Dessa forma percebe-se que a educação infantil passou por uma transformação de objetivos aos olhos da escola e do Estado. A escola de educação infantil adquiriu um caráter educador e não apenas cuidador, o que fez com que se reinventasse em seus métodos pedagógicos:

Nesse sentido a Educação Infantil tem uma função pedagógica, tomando a realidade e os conhecimentos infantis como ponto de partida e os ampliando através de atividades que tenham significado concreto para a vida das crianças e, simultaneamente que assegurem a aquisição de novos conhecimentos. (BRANDOLI, 2012)

Para assegurar a qualidade na educação infantil, é necessário que haja colaboração entre gestores, docentes, familiares e as próprias crianças. Para a UNICEF (2018) é a gestão democrática que garante a qualidade na educação infantil.

Segundo o Censo Escolar (INEP, 2017) atualmente o Brasil conta com aproximadamente 116,5 mil unidades de educação infantil, sendo 8,5 milhões de crianças, com idade até 5 anos, matriculadas. Dessa 
forma para que se haja qualidade no ensino, a UNICEF (2018) afirma que é necessário um processo de autoavaliação das escolas, e a fiscalização do Estado para que haja a efetiva implementação dos objetivos para a educação infantil e a manutenção da qualidade:

A metodologia de autoavaliação escolar é composta por sete dimensões: Planejamento institucional; Multiplicidade de experiências e linguagens; Interações; Promoção da saúde; Espaços, materiais e mobiliários; Formação e condições de trabalho dos (as) professores (as) e demais profissionais; Cooperação e troca com as famílias e participação na rede de proteção social. (UNICEF, 2018)

Dessa forma, é notável uma maior abrangência de objetivos para a educação infantil, os profissionais que lidam com as crianças devem construir sua pedagogia, com um olhar inovador sobre o conceito da criança como o sujeito da educação (ZABALZA, 2007).

A partir dessa perspectiva é que se dará a nova adoção do modelo curricular, com base na legislação e nas novas metodologias de ensino. Para Zabalza (2007) para que se obtenha qualidade no Ensino Infantil as instituições devem reforçar a sua identidade e autonomia na direção formativa dos alunos. Esse conceito, por sua vez, vem auxiliado da ideia de gestão democrática e autônoma na construção de suas próprias políticas pedagógicas que respeitem a realidade sociocultural e ambiental em que a comunidade escolar está inserida.

Em 2014 a Lei n. 13.005, aprovou o Plano Nacional da Educação para todo o território nacional estabelecendo metas especificas para o ciclo inicial da educação básica. 0 ciclo de monitoramento, em específico, serve ao objetivo de mensurar resultados da educação em todo o país, segundo as metas para a política que estão presentes na lei 13.005 de 2014.

O Plano Nacional de Educação estabelece que as pedagogias aplicadas à educação infantil devem considerar a criança de forma integral, isto é, considerar sua visão de mundo através do brincar e não se dissociar do cuidar e educar (BRASIL, 2014).

Para o profissional da educação infantil, a especificação é que o mesmo deve ter formação de educador, à qual será requisitada para exercer a função de professor da educação infantil. É dever da gestão pública, segundo o PNE (2014), garantir que as escolas sejam adequadas para a acessibilidade de todas as crianças e que se tenham materiais que garantam uma experiência de qualidade no ensino, inclusive com as crianças portadoras de necessidades especiais.

O documento ainda afirma que a educação infantil segue articulada à outras políticas de proteção e assistência à criança para que se tenha garantia de um desenvolvimento integral (BRASIL, 2014).

A Base Nacional Comum Curricular - BNCC (2017) afirma que é direito da criança durante sua aprendizagem e desenvolvimento: conviver com o grupo social escolar, brincar, participar ativamente da gestão das propostas da escola e das atividades elaboradas pela mesma, ter contato explorador com cores e sons, texturas e gestos, expressar-se por meio do diálogo criativo e conhecer e afirmar sua identidade (BRASIL, 2017).

Pela BNCC (BRASIL, 2017) nota-se que a concepção da criança como sujeito ativo na educação e aprendizagem, leva em conta aspectos de seu desenvolvimento afetivo, social e crítico para a elaboração das propostas curriculares, porém não deixa de guiar-se pelo objetivo primário educativo que corresponde ao 
papel da escola:

Essa concepção de criança como ser que observa, questiona, levanta hipóteses, conclui, faz julgamentos e assimila valores e que constrói conhecimentos e se apropria do conhecimento sistematizado por meio da ação e nas interações com o mundo físico e social não deve resultar no confinamento dessas aprendizagens a um processo de desenvolvimento natural ou espontâneo. Ao contrário, impõe a necessidade de imprimir intencionalidade educativa às práticas pedagógicas na Educação Infantil, tanto na creche quanto na pré-escola. (BRASIL, 2017)

Para fiscalizar e auxiliar na melhora da qualidade da Educação Infantil, o Mistério da Educação junto à Secretaria de Educação elaborou os Indicadores de Qualidade na Educação Infantil (BRASIL, 2009). Esse documento tem como proposta o monitoramento das escolas de Educação Infantil através do método de autoavaliação das mesmas guiadas pelas diretrizes das cartilhas elaboradas.

O projeto tem como intencionalidade principal guiar as escolas para a construção de "práticas educativas que respeitem os direitos fundamentais da criança e ajudem a construir uma sociedade mais democrática" (BRASIL, 2009).

Em 2011 foi feito um levantamento sobre a funcionalidade dos Indicadores de Qualidade, constatouse que apesar de o número de respondentes às questões de autoavaliação escolar não ser baixo ainda é necessária uma maior orientação sobre o uso da proposta (BRASIL, 2011).

\section{CONCLUSÕES}

Os fatores que compõem a padronização da qualidade na Educação Infantil, não funcionam como uma fórmula fechada, sendo aberto à inúmeras possibilidades de análise e discussões, o que possibilita a ação construtiva dos profissionais ligadas à Educação Infantil em busca de métodos que otimizem a qualidade pedagógica e institucional.

Para a construção da qualidade na Educação Infantil é necessária primordialmente a ação conjunta do Estado, que regula e padroniza a educação, estabelecendo diretrizes que norteiam o trabalho dos gestores, além de afirmar os direitos das crianças e os objetivos para sua formação.

Com a pesquisa compreende-se que a Educação Infantil passou da perspectiva de assistencialismo fornecido pelo Estado à um objetivo de sociabilização e educação já na primeira infância, como direito fundamental da criança. A Educação infantil passa, então, a partir da década de 1980, objetivar a construção de conhecimentos científicos exercendo importante papel na sociabilização das crianças e no preparo para a cidadania e participação crítica e ativa em sociedade.

Para a prática gestora na Educação Infantil objetiva-se a qualidade de educação para as crianças, apesar das inúmeras legislações que incentivam a gestão democrática em busca de um aprendizado ativo nessa fase, ainda há a necessidade de incentivos e estímulos para que a Educação Infantil atinja seus objetivos.

A qualidade do ensino depende de múltiplos fatores e agentes que perpassam a gestão, sendo um trabalho a ser realizado por toda a comunidade escolar na perspectiva de uma gestão democrática e participativa em que o aluno seja o centro das preocupações para as medidas que otimizem os processos 
educacionais. Cabe ao gestor organizar esse espaço de debate e reflexão ampliando a participação dos agentes educacionais e os pais, para que se tenha um sentimento de pertencimento no ambiente escolar.

\section{REFERÊNCIAS}

ANDRADE, L. B. P.. Educação Infantil: discursos, legislação e práticas institucionais. São Paulo: UNESP, 2010.

BRANDOLI, F. M.. Educação Infantil: a inversão da dicotomia entre o ensino público e o privado. Revista Educação por Escrito, v.3, n.1, 2012.

BRASIL. Constituição Federal da República do Brasil de 1934. Emendas Constitucionais de Revisão. Brasília: DOU, 1934.

BRASIL. Constituição Federal da República do Brasil de 1988. Emendas Constitucionais de Revisão. Brasília: DOU, 1988.

BRASIL. Lei N. 13.005, de 25 de junho de 2014. Aprova o Plano Nacional de Educação - PNE e dá outras providências. Brasília: DOU, 2014.

BRASIL. Lei N. 8.069, de 13 de julho de 1990. Dispõe sobre o Estatuto da Criança e do Adolescente e dá outras providências. Brasília: DOU, 1990.

BRASIL. Lei N. 9.394 de 20 de dezembro de 1996. Estabelece as diretrizes e bases da educação nacional. Brasília: DOU, 1996.

BRASIL. Ministério da Educação e Cultura. Base Nacional Comum Curricular: Educação Infantil e Ensino Fundamental. Brasília: Ministério da Educação, 2017.

BRASIL. Ministério da Educação. Indicadores de Qualidade na Educação Infantil. Brasília: MEC, 2009.

BRASIL. Ministério da Educação. Monitoramento do uso dos Indicadores de Qualidade na Educação Infantil. Brasília: MEC, 2011.
CAMPOS, R. F.. "Política pequena" para as crianças pequenas? Experiências e desafios no atendimento das crianças de 0 a 3 anos na América Latina. Revista Brasileira de Educação, v.17, n.49, 2012.

DIDONET, V.. Creche: a que veio para onde vai. Em Aberto, Brasília, v.16, n.73, p.11-27, 2001.

INEP. Instituto Nacional de Estudos e Pesquisas Educacionais Anísio Teixeira. Censo Escolar: Matriculas Educação Infantil. Brasília: INEP, 2017.

LUCAS, M. A. O. F.. A influência do UNICEF e da UNESCO na educação infantil brasileira contemporânea. Revista HISTEDBR, Campinas, n.35, p.126-140, 2009.

PASCHOAL, J. D.; MACHADO, M. C. G.. A história da educação infantil no Brasil: avanços, retrocessos e desafios dessa modalidade educacional. Revista HISTEDBR, Campinas, n.33, p.78-95, 2009.

ROSEMBERG, F.. Políticas de educação infantil e avaliação. Cadernos de Pesquisa, v.45, n.148, p.44-77, 2013.

UNESCO. Organização das Nações Unidas para a Educação, a Ciência e a Cultura. Educação para todos: o compromisso de Dakar. Brasília: UNFSCO, 2001

UNICEF. Fundo de Emergência Internacional das Nações Unidas. Indicadores de qualidade na educação infantil. Brasília: UNICEF, 2018.

ZABALZA, M. A.. Qualidade em educação infantil. Porto Alegre: Artmed, 2007.

A CBPC - Companhia Brasileira de Produção Científica (CNPJ: 11.221.422/0001-03) detém os direitos materiais desta publicação. Os direitos referem-se à publicação do trabalho em qualquer parte do mundo, incluindo os direitos às renovações, expansões e disseminações da contribuição, bem como outros direitos subsidiários. Todos os trabalhos publicados eletronicamente poderão posteriormente ser publicados em coletâneas impressas sob coordenação da Sustenere Publishing, da Companhia Brasileira de Produção Científica e seus parceiros autorizados. Os (as) autores (as) preservam os direitos autorais, mas não têm permissão para a publicação da contribuição em outro meio, impresso ou digital, em português ou em tradução. 